\title{
Application of bromate-bromide mixture as a green brominating agent for the determination of fexofenadine hydrochloride in pharmaceutical dosage form
}

\begin{abstract}
The present study describes one titrimetric and two spectrophotometric methods for the determination of fexofenadine hydrochloride (FFH) in bulk drug and in tablets based on bromination of FFH by bromine generated in situ by the action of acid on bromate-bromide mixture. In titrimetry, FFH is treated with a known excess amount of bromate-bromide mixture in acid medium followed by the determination of unreacted bromine iodometrically (method A). In spectrophotometry, the residual bromine is determined by its reaction with excess iodide and the liberated iodine $\left(\mathrm{I}_{3}{ }^{-}\right)$is either measured at $360 \mathrm{~nm}(\operatorname{method} B)$ or iodine reacted with starch followed by the measurement of the blue colored starch-iodide complex at $570 \mathrm{~nm}$ (method C). Titrimetry allows the determination over the range of 4.5$30.0 \mathrm{mg}$ FFH whereas in spectrophotometry, Beer's law is obeyed in the concentration ranges of 2-20.0 and 0.6-6.0 $\mathrm{g} \mathrm{mL}^{-1} \mathrm{FFH}$ for method B and method C, respectively. The molar absorptivities are calculated to be $2.2 \times 10^{4}$ and $5.3 \times 10^{4} \mathrm{~L} \mathrm{~mol}^{-1} \mathrm{~cm}^{-1}$ for method $\mathrm{B}$ and method C, respectively, and the corresponding Sandell sensitivity values are 0.0238 and $0.0101 \mu \mathrm{g} \mathrm{cm}^{-2}$. The limits of detection and quantification are also reported for both the spectrophotometric methods. The proposed methods were applied successfully to the determination of FFH in raw material and commercial tablets. Statistical comparison of the results was performed using Student's t-test and F-ratio at 95\% confidence level and there was no significant difference between the official and proposed methods with regard to accuracy and precision. Further, the validity of the proposed methods was confirmed by recovery studies via standard addition technique.
\end{abstract}

Keywords: fexofenadine, bromate-bromide, pharmaceuticals, titrimetry, spectrophotometry; assay
Volume 7 Issue I - 2018

\author{
Raghu MS,' Shantharam CS, ${ }^{2}$ Yogesh Kumar \\ $\mathrm{K}^{3}$ \\ Department of Chemistry, Nitte Meenakshi Institute of \\ Technology, India \\ 2Department of Chemistry, Pooja Bhagavat Memorial Mahajana \\ PG Centre, India \\ ${ }^{3}$ Department of Chemistry, Jain University, India
}

Correspondence: Raghu MS, Department of Chemistry, Nitte Meenakshi Institute of Technology, 560064, Bangalore, India, Email raghuhassan2009@gmail.com

Received: December 15, 2017 | Published: January 12, 2018
Abbreviations: FFH, fexofenadine hydrochloride; HPLC, high performance liquid chromatographic; USP, united states pharmacopeia; CAT, Chloramine-T

\section{Introduction}

Fexofenadine hydrochloride (FFH), chemically known as ( \pm )-4-1-hydroxy-4-[4-(hydroxydiphenylmethyl)-1-piperidinylbutyl]-a,a-dimethyl benzene aceticacid hydrochloride. ${ }^{1}$ is a active metabolite of terfenadine and is a second-generation histamine $\mathrm{H}_{-}$receptor antagonist in piperidine-class drugs. These drugs are used in the treatment of seasonal allergic rhinitis, chronic idiopathic urticaria etc. $\mathrm{FFH}$ is a $\mathrm{H}_{-}$-receptor antagonist that blocks peripheral histamine $\mathrm{H}_{1}$-receptors selectively. It does not cause sedation or other central nervous system effects because it does not cross the blood-brain barrier (Figure 1). ${ }^{2}$

FFH is official in United States Pharmacopeia (USP), ${ }^{3}$ which describes a high performance liquid chromatographic (HPLC) method for its assay. Literature survey revealed the availability of few methods for the assay of FFH in pharmaceuticals. Quantification of FFH has been achieved by high performance liquid chromatography (HPLC), ${ }^{4-13}$ spectroflurimetry, ${ }^{14}$ capillary electrophoresis, ${ }^{15}$ cyclic voltammetry ${ }^{16}$ and UV-spectrophotometry. ${ }^{17-19}$ Direct potentiometric and potentiometric titrations methods employing polymeric membrane sensors were developed by Abbas et al. ${ }^{20}$ the titrimetric method involved potentiometric titration of the drug with phosphomolybdic acid and membrane sensors were used for end point detection. ${ }^{20}$ Some of these methods have sufficient sensitivity to determine lower concentrations of the drug. However, these methods involve several manipulation steps which are not simple for routine analysis of pharmaceutical formulations and require sophisticated instruments. To the best of our knowledge, no visual titrimetirc method has ever been reported for FFH. Visual titrimetry and visible spectrophotometry may serve as an useful alternatives to many of the aforesaid sophisticated techniques because of their cost-effectiveness, ease of operation, sensitivity, fair accuracy and precision and wide applicability.

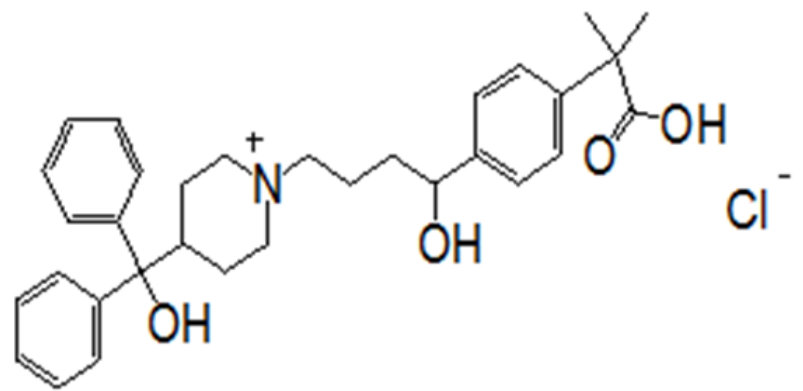

Figure I Structure of FFH.

Narayana et al. ${ }^{21}$ developed two methods for the determination of FFH in bulk drug and in its tablet form. In their procedures, FFH was treated with a measured excess of chloramine-T (CAT), and the 
unreacted oxidant was reacted with malachite green or xylene cyanol $\mathrm{FF}$, and the change in absorbance was measured at 615 or $612 \mathrm{~nm}$. Apart from this, quite a few extractive spectrophotometric methods based on ion-pair formation reaction of FFH with dyes have also been reported. Suresh et $a .^{22}$ have reported a method based on the formation of chloroform-soluble ion-associate complex by the with bromothymol blue at $\mathrm{pH} 2.6$ followed by absorbance measurement at $412 \mathrm{~nm}$. Beer's law is obeyed over the concentration range $10-50 \mu \mathrm{gmL}^{-1} \mathrm{FFH}$. The drug has also been determined spectrophotometrically based on ionpair complex formation with chromotrope $2 \mathrm{R}^{23}$ at $\mathrm{pH} 5.0$ followed by extraction into methylene chloride and measurement at $512 \mathrm{~nm}$. Alaa et al. ${ }^{24}$ devised extractive spectrophotometric methods for the estimation of FFH based on ion- pair reaction employing some acidic dyes viz, bromothymol blue, bromophenol blue, bromocresol green and bromocresol purple. Based on similar reaction, Srinivas et al. ${ }^{25}$ have also developed another method in which chloroform-soluble ionassociate complex formed by the interaction of drug with safranin-O or methylene blue at $\mathrm{pH} 9.8$ were measured at 520 or $650 \mathrm{~nm}$. Another method based on the formation of charge transfer complex between FFH and 4-chloro-7-nitro-2,1,3-benzoxadiazole (NBD-Cl) in nonaqueous medium. The method was applicable over a concentration range of $10-50 \mu \mathrm{gmL}^{-1} \cdot{ }^{26}$ Soad et al. ${ }^{27}$ developed a method based on oxidation of the drug with alkaline potassium permanganate where a green color peaking at $607 \mathrm{~nm}$ is produced. Beer's law was obeyed in the range $0.25-1.12 \mu \mathrm{gmL}^{-1}$. Another spectrophotometric determination of some antihistaminic and skeletal muscle relaxant drugs through ion-pair formation with xylene cyanol and orange $G$ was also found in the literature. ${ }^{28}$

The visible spectrophotometric methods currently available suffer from one or the other disadvantage such as critical dependence on $\mathrm{pH}$, poor sensitivity, labor-intensive, tedious and time-consuming liquid-liquid extraction step, use of large amount of organic solvents as indicated in Table 1. Extraction methods in general are prone to loss of analyte leading to erroneous results. The scientific references found in the CAS and SCI database, relating to green analytical chemistry or environmental-friendly analytical methods have been growing significantly in recent years and the recent development of new analytical methods with good characteristics such as selectivity and sensitivity are not sufficient; modern analytical methods need to be green..$^{29}$ Hence, the aim of this study was to develop three methods for the determination of FFH based on bromination reaction of FFH by an eco-friendly and green brominating agent (i.e. bromine-generated in situ by the action of the acid on bromate-bromide mixture), and potassium iodide and starch as auxiliary reagents. The reaction conditions were thoroughly studied, and under optimum conditions, the procedures provide highly sensitive and selective assays for FFH in commercial dosage forms. The proposed methods offer the advantage of simplicity, speed, accuracy and precision besides being free from interference from common tablet excipients.

\section{Experimental}

\section{Instrument}

A Systronics model 106 digital spectrophotometer (Systronics, Ahmedabad, Gujarat, India) provided with $1 \mathrm{~cm}$ matched quartz cells was used for all absorbance measurements.

\section{Reagents and materials}

All reagents and chemicals used were of analytical or pharmaceutical grade and distilled water was used to prepare the solutions.

\section{Bromate-bromide mixture}

A stock standard solution of bromate-bromide mixture equivalent to $5 \mathrm{mM} \mathrm{KBrO}_{3}$ and 10 -fold molar excess of $\mathrm{KBr}$ was prepared by dissolving accurately weighed $0.209 \mathrm{~g}$ of potassium bromate (S. D. Fine- Chem. Ltd., Mumbai, India) and $1.488 \mathrm{~g}$ of potassium bromide (Merck, Mumbai, India) in water and diluting to volume in a $250 \mathrm{~mL}$ calibrated flask, and directly used in the titrimetric method. Another stock standard solution of $\mathrm{KBrO}_{3}-\mathrm{KBr}$ equivalent to $300 \mu \mathrm{gmL}$ ${ }^{1} \mathrm{KBrO}_{3}$ was prepared by dissolving $30 \mathrm{mg}$ of $\mathrm{KBrO}_{3}$ and $300 \mathrm{mg} \mathrm{KBr}$ in a $100 \mathrm{~mL}$ calibrated flask and this was diluted appropriately with water to get working concentrations equivalent to 30 and $15 \mu \mathrm{gmL}$ ${ }^{1}$ in $\mathrm{KBrO}_{3}$ for use in spectrophotometric method $\mathrm{B}$ and method $\mathrm{C}$, respectively.

\section{Potassium iodide}

A $5 \%$ potassium iodide (Merck, Mumbai, India) solution was prepared by dissolving $5 \mathrm{~g}$ potassium iodide with water in a $100 \mathrm{~mL}$ calibrated flask. This solution was prepared a fresh daily. A $2 \%$ solution was prepared separately for spectrophotometric work.

\section{Starch solution}

One gram of starch (LOBA Chemie Ltd., Mumbai, India) was made in to paste with water and slowly poured with constant stirring into $100 \mathrm{~mL}$ boiling water, boiled for $5 \mathrm{~min}$, cooled and used. This solution was prepared freshly every day.

\section{Hydrochloric acid}

Concentrated acid (Merck, Mumbai, India, Sp. gr. 1.18) was diluted appropriately with water to get $2 \mathrm{M} \mathrm{HCl}$ for use in all methods.

\section{Sodium acetate}

A $3 \mathrm{M}$ aqueous solution of sodium acetate was prepared by dissolving suitable quantity of sodium acetate trihydrate crystals (Merck, Mumbai, India) in water for use in method B.

\section{Standard solution of FFH}

Pharmaceutical grade fexofenadine hydrochloride certified to be $99.89 \%$ pure was received from Sanofi Aventis Pharma India, Mumbai, India, as gift and was used as received. A stock standard solution equivalent to $3.0 \mathrm{mgmL}^{-1}$ of FFH was prepared by dissolving accurately weighed $750 \mathrm{mg}$ of pure drug in 1:2 (acetic acid: water) and diluted to mark in a $250 \mathrm{~mL}$ calibrated flask with the same solvent. The solution $\left(3 \mathrm{mgmL}^{-1} \mathrm{FFH}\right)$ was used in titrimetric work and diluted appropriately with water to get the working concentrations of 40 and $12 \mu \mathrm{g} \mathrm{mL}^{-1} \mathrm{FFH}$ for use in spectrophotometric method B and method C, respectively. The pharmaceutical preparations Allegra-180 and Allegra-120 (both from Aventis Pharma Ltd, Ankleshwar, India) were purchased from commercial sources in the local market and subjected to analysis.

\section{Recommended procedures}

\section{Method A (titrimetry)}

Different volumes $(1.5-10 \mathrm{~mL})$ of standard FFH $\left(3 \mathrm{mgmL}^{-1}\right)$ solution were measured accurately, transferred into a $100 \mathrm{~mL}$ iodine flask and the total volume was made to $10 \mathrm{~mL}$ with water. The solution was acidified by adding $5 \mathrm{~mL}$ of $2 \mathrm{M} \mathrm{HCl}$ followed by the addition of $10 \mathrm{~mL}$ of bromate-bromide mixture $\left(5 \mathrm{mM}^{\text {in }} \mathrm{KBrO}_{3}\right)$ using a pipette. The content was mixed well and the flask was kept aside for $10 \mathrm{~min}$ with occasional swirling. Then, $5 \mathrm{~mL}$ of $5 \%(\mathrm{w} / \mathrm{v})$ potassium iodide 
was added to the flask and the liberated iodine was titrated with $0.03 \mathrm{M}$ sodium thiosulphate to a starch end point. A blank titration was performed under the same conditions taking $10 \mathrm{~mL}$ of acetic acid: water $(1: 2)$ mixture. The drug content in the measured aliquot was calculated from the following equation:

$$
\operatorname{Amount}(m g)=\frac{(B-S) \times \text { Mol.wt } \times R}{n}
$$

where B is volume of the titrant in the absence of the drug, $\mathrm{S}$ is volume of the titrant in the presence of the drug, Mol. wt is relative molecular mass of the drug, $\mathrm{R}$ is molarity of bromate in the bromatebromide mixture and $\mathrm{n}$ is the reaction stoichiometry (number of moles of bromate reacting with each mole of FFH).

\section{Spectrophotometric method B (based on the measurement of tri-iodide ion)}

Varying aliquots $(0.5-5.0 \mathrm{~mL})$ of standard FFH solution $(40 \mu \mathrm{g} \mathrm{mL}$ $\left.{ }^{1}\right)$ were accurately transferred into a series of $10 \mathrm{~mL}$ calibrated flasks and the total volume was adjusted to $5.0 \mathrm{~mL}$ with water. OnemL of $2 \mathrm{M} \mathrm{HCl}$ was added to each flask followed by the addition of $1 \mathrm{~mL}$ bromate-bromide mixture solution $\left(30 \mu \mathrm{g} \mathrm{mL}^{-1}\right.$ in $\left.\mathrm{KBrO}_{3}\right)$. The content was mixed well and let stand for $10 \mathrm{~min}$ with occasional shaking. Then, $1.0 \mathrm{~mL}$ of $3 \mathrm{M}$ sodium acetate solution was added to each flask followed by $1 \mathrm{~mL}$ of $2 \%$ potassium iodide. The volume was brought to the mark with water and the absorbance of the resulting tri-iodide ion was measured at $360 \mathrm{~nm}$ after $5 \mathrm{~min}$ against the water.

\section{Spectrophotometric method C (based on the measurement of starch-iodine chromogen)}

Into a series of $10 \mathrm{~mL}$ calibrated flasks, different aliquots $(0.5-$ $5.0 \mathrm{~mL})$ of standard FFH $\left(12 \mu \mathrm{g} \mathrm{mL}^{-1}\right)$ solution were transferred using a micro burette. The total volume in each flask was brought to $5 \mathrm{~mL}$ by adding required quantity of water. The solution was acidified by adding $1 \mathrm{~mL}$ of $2 \mathrm{M} \mathrm{HCl}$, and $1 \mathrm{~mL}$ of bromate-bromide $\left(15 \mu \mathrm{g} \mathrm{mL}^{-1}\right.$ in $\mathrm{KBrO}_{3}$ ) solution was then added to each flask. The flasks were kept aside for $10 \mathrm{~min}$ with periodic shaking; $1 \mathrm{~mL}$ of $2 \%$ potassium iodide was added and the content was mixed well. After $5 \mathrm{~min}, 1 \mathrm{~mL}$ of $1 \%$ starch solution was added to each flask and the volume was made up to the mark with water and mixed well. The absorbance of the resulting blue chromogen was measured at $570 \mathrm{~nm}$ against water blank after $5 \mathrm{~min}$.

A standard graph was prepared by plotting absorbance against concentration and the unknown concentration was read from the graph or computed from the regression equation derived using Beer's law data.

\section{Procedure for tablets}

Twenty tablets each containing $180 \mathrm{mg}$ or $120 \mathrm{mg}$ of $\mathrm{FFH}$ were weighed and finely powdered. An amount of the powder equivalent to $300 \mathrm{mg}$ of FFH was accurately weighed and transferred to a $100 \mathrm{~mL}$ calibrated flask, $60 \mathrm{~mL}$ of acetic acid: water $(1: 2)$ mixture was added and the content was shaken thoroughly for about $20 \mathrm{~min}$. The volume was diluted to the mark with same solvent, mixed well and filtered using Whatman No. 42 filter paper. The first $10 \mathrm{~mL}$ portion of the filtrate was discarded and a suitable aliquot of the filtrate was assayed by titrimetric procedure. The same tablet extract $\left(3 \mathrm{mg} \mathrm{mL}^{-1} \mathrm{FFH}\right)$ was appropriately diluted with water to get 40 and $12 \mu \mathrm{g} \mathrm{mL}^{-1}$ with respect to FFH for the assay by the spectrophotometric method B and method $\mathrm{C}$, respectively.

\section{Procedure for the analysis of placebo blank and synthetic mixture}

A placebo blank containing starch (50mg), acacia (45mg), hydroxyl cellulose $(60 \mathrm{mg})$, sodium citrate $(70 \mathrm{mg})$ lactose $(20 \mathrm{mg})$, talc $(60 \mathrm{mg})$, acacia $(30 \mathrm{mg})$ magnesium stearate $(55 \mathrm{mg})$ and sodium alginate $(60 \mathrm{mg})$ was prepared, and $50 \mathrm{mg}$ of the placebo blank was extracted with 1:2 (acetic acid:water) mixture and the solution was made as described under "Procedure for the tablets" and then subjected to analysis.

A synthetic mixture was prepared by adding $150 \mathrm{mg}$ of FFH to about 40mg of the placebo blank prepared above, homogenized and the solution was prepared as done under "Procedure for the tablets". The filtrate was collected in a $50 \mathrm{~mL}$ flask. The synthetic mixture solution was analysed by titrimetry and then appropriately diluted with water to get 40.0 and $12.0 \mathrm{mg} \mathrm{mL}^{-1} \mathrm{FFH}$ solutions, and appropriate aliquots were subjected to analysis by method B and method C, separately.

\section{Results and discussion}

Bromate-bromide mixture in acid medium behaves as an equivalent solution of bromine and has been used for the assay of several organic pharmaceutical compounds. ${ }^{30-33}$ From the preliminary experiments, FFH was found to undergo bromination reaction. The present study describes one titrimetric and two spectrophotometric procedures for the determination of FFH using bromine generated in situ as a green brominating agent and are based on the bromination reaction of FFH with a known excess of bromate-bromide mixture in acid medium through eletrophilic substitution reaction. The main advantages of this reagent are replacement of the highly toxic and hazardous liquid bromine, no formation of hazardous byproducts, and use of eco-friendly and easily available chemicals. The proposed methods entail the addition of a measured excess of bromate-bromide mixture in acid medium to FFH followed by determination of the residual bromine after the reaction between the drug and bromine is judged to be complete. In titrimetry, the reaction which was found to follow a 1:2 (FFH: $\mathrm{KBrO}_{3}$ ) stoichiometry was followed by back titration of the unreacted bromine iodometrically, whereas in spectrophotometry, the amount of iodine liberated, by the reaction of unreacted bromine with potassium iodide, was either measured directly at $360 \mathrm{~nm}$ or reacted with starch and resulting blue colored chromogen of starch-iodine complex was measured at $570 \mathrm{~nm}$. In all methods, the amount of reacted bromate (in situ bromine) corresponded to the amount of FFH which formed the basis of the assay. The possible reaction pathways are proposed and illustrated in Scheme 1.

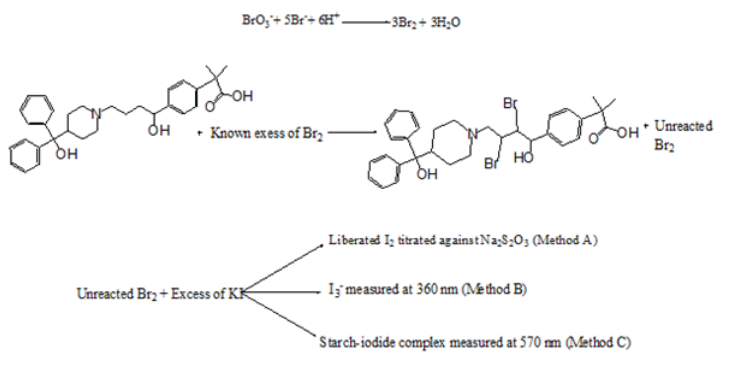

Scheme I Tentative reaction pathway for proposed methods.

\section{Method development}

The various experimental conditions providing accurate and precise results were carefully optimized. 


\section{Titrimetry}

The proposed titrimetric procedure is based on bromination reaction between FFH and bromine generated in situ. A 4.5-30mg of FFH were treated with known excess of bromate-bromide mixture in acid medium, and back titrating the unreacted bromine iodometrically after ensuring the completion of the reaction. Hydrochloric acid medium was found to be ideal and at optimum concentration $(5 \mathrm{~mL}$ of $2 \mathrm{M} \mathrm{HCl}$ in a total volume of $25 \mathrm{~mL}$ ), the reaction was completedwithin $10 \mathrm{~min}$. At lower acid concentration $(\leq 3.0 \mathrm{~mL}$ of $2 \mathrm{M} \mathrm{HCl})$ the reaction stoichiometry was slightly less than 2 and at higher acid concentration $(\geq 7.0 \mathrm{~mL}$ of $2 \mathrm{M} \mathrm{HCl})$ the reaction stoichiometry was slightly higher than 2. Also the reaction stoichiometry was unaffected when (1.3-2.6) $\mathrm{M} \mathrm{HCl}$ was maintained. Hence, $5 \mathrm{~mL}$ of $2 \mathrm{M} \mathrm{HCl}$ in a total volume of $25 \mathrm{~mL}$ (2.0M overall) was used. Hence, $5 \mathrm{~mL}$ of $2 \mathrm{M} \mathrm{HCl}$ was found adequate to be used in the titrimetric study. The reaction was found to be complete in $10 \mathrm{~min}$ and contact time up to $20 \mathrm{~min}$ had no effect on the stoichiometry or the results. Ten milliliters volume of $5 \mathrm{mM}$ $\mathrm{KBrO}_{3}-50 \mathrm{mM} \mathrm{KBr}$ was found adequate for a quantitative bromination of FFH in the range investigated.

\section{Spectrophotometry}

In spectrophotometric methods, the amount of iodine liberated, by the reaction of unreacted bromine with potassium iodide, was either measured directly at 360 in method B or iodine is reacted with starch and resulting blue colored chromogen of starch-iodide complex is measured at $570 \mathrm{~nm}$ for method C (Figure 2).

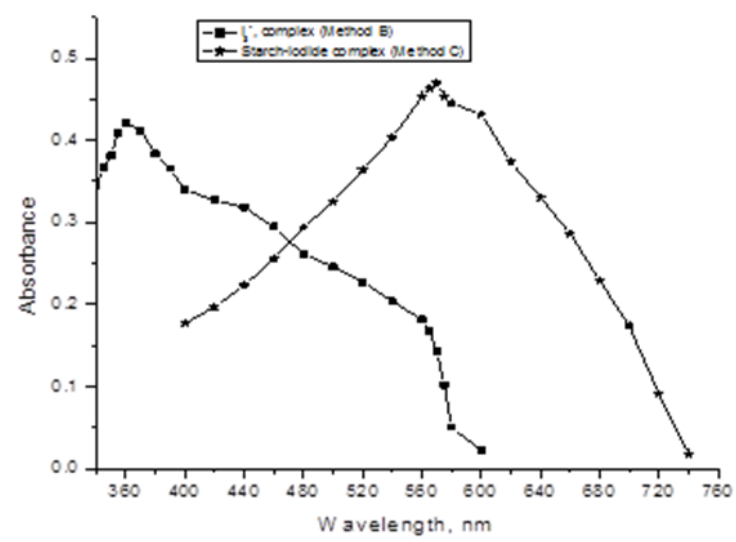

Figure 2 Absorption spectra: $12 \mu \mathrm{g} \mathrm{ml^{-1 }} \mathrm{FFH}$, tri-iodate ion (Method B): $3.6 \mu \mathrm{g}$ $\mathrm{ml}^{-1} \mathrm{FFH}$, starch-iodide complex (Method C).

\section{Optimization of experimental variables}

Selection of the solvent: FFH is insoluble in many solvents like water, chloroform, dichloromethane, toluene, ethyl acetate and acetone. Even though FFH is soluble in methanol and ethanol, these solvents suppress the liberation of iodine, thus could not be used. Among the tested solvents, acetic acid was found to be an ideal solvent for the preparation of the standard solution of $\mathrm{FFH}$, and the minimum ratio to get a stable solution was 1: 2 (acetic acid: water) for $3.0 \mathrm{mgmL}^{-1}$

Effect of acid concentration: The reaction between FFH and bromate-bromide was performed in different acid media. Better results were obtained in hydrochloric acid medium. The effect of acid concentration on the reaction between FFH and bromatebromide was studied by varying the concentration of $\mathrm{HCl}$ keeping the concentrations of bromate-bromide and drug fixed. The reaction was found to be rapid yielding a constant absorbance with maximum sensitivity and stability when the $\mathrm{HCl}$ concentration was maintained in the range of $0.08-0.5 \mathrm{M}(0.25 \mathrm{~mL}-2 \mathrm{~mL} 2 \mathrm{M} \mathrm{HCl})$ acid concentration was found sufficient for the instantaneous reaction between unreacted bromate-bromide and potassium iodide. Therefore, $1 \mathrm{~mL}$ of $2 \mathrm{M} \mathrm{HCl}$ in a total volume of $8 \mathrm{~mL}(0.3 \mathrm{M})$ was used in both methods

Reaction time and color stability: The effect of time on the reaction between $\mathrm{FFH}$ and bromate-bromide mixture in the presence of $\mathrm{HCl}$ was studied by keeping all other reaction conditions unchanged. The absorbance of the colored species was measured after different reaction times $(5.0-90.0 \mathrm{~min})$ and the results showed that the reaction was complete within 10min in both the methods. The yellow tri-iodide ion in method B was stable upto $45 \mathrm{~min}$ where as the absorbance of the blue colored starch-iodine complex chromogen in method $\mathrm{C}$ remained stable for at least $1 \mathrm{hr}$.

Role of sodium acetate: The liberation of iodine did not stop even after 30 min under the specified acidic conditions, but on adding sodium acetate the reaction ceased immediately. The amount of sodium acetate required was optimized and $1 \mathrm{~mL}$ of $3 \mathrm{M}$ sodium acetate in a total volume of $10 \mathrm{~mL}$ was found optimum.

\section{Method validation}

Linearity, detection and quantification limits: Under the optimum conditions a linear relation was obtained between absorbance and concentration of FFH in the ranges given in Table 1. The calibration graph in each instance is described by the equation:

$$
Y=a+b X
$$

(Where $\mathrm{Y}=$ absorbance, $\mathrm{a}=$ intercept, $\mathrm{b}=$ slope and $\mathrm{X}=$ concentration in $\mu \mathrm{g} \mathrm{mL}^{-1}$ ). The correlation coefficient, intercept and slope for the calibration data are summarized in Table 1. Sensitivity parameters such as apparent molar absorptivity and sandell sensitivity values, the limits of detection (LOD) and quantification (LOQ) are calculated as per the current ICH guidelines. ${ }^{34}$ and compiled in Table 2. LOD and LOQ were calculated according to the same guidelines using the following formulae:

$$
L O D=\frac{3.3 \times \sigma}{S} \quad \& \quad L O Q=\frac{10 \times \sigma}{S}
$$

where $\sigma$ is the standard deviation of six reagent blank determinations and $\mathrm{s}$ is the slope of the calibration curve.

Accuracy and precision: The precision and accuracy of the proposed methods were studied by repeating the experiment seven times within the day to determine the repeatability (intra-day precision) and five times on different days to determine the intermediate precision (interday precision) of the methods. These assays were performed for three levels of analyte. The results of this study are summarized in Table 3 . The percentage relative standard deviation (RSD, \%) values were $\leq 77 \%$ (intra-day) and $\leq 2.38 \%$ (inter-day) indicating good precision of the methods. Accuracy was evaluated as percentage relative error (RE, \%) between the measured mean concentrations and taken concentrations for FFH. The value of RE ( $\%$ ) was $\leq 2.89 \%$ demonstrate the high accuracy of the proposed methods.

Robustness and ruggedness: The robustness of the methods was evaluated by making small incremental changes in the volume of reagent and contact time, and the effect of these changes was studied on the absorbance of the formed colored product. The changes had negligible influence on the results as revealed by small intermediate precision values expressed as RSD $(\leq 64 \%)$. 
Table I Comparison of the performance characteristics of the proposed methods with the existing visible spectrophotometric methods

\begin{tabular}{|c|c|c|c|c|c|c|}
\hline SI. No. & Reagent/s Used & Methodology & $\operatorname{Imax}(n \mathrm{~nm})$ & $\begin{array}{l}\text { Linear Range } \\
(\mu g / \mathrm{ml})(\varepsilon=\mathrm{L} / \\
\mathrm{mol} / \mathrm{cm})\end{array}$ & Remarks & Ref \\
\hline \multirow[b]{2}{*}{ I } & $\begin{array}{l}\text { a)Chloramine -T-malachite } \\
\text { green }\end{array}$ & $\begin{array}{l}\text { Unrected chloramine } \mathrm{T} \\
\text { measured }\end{array}$ & 615 & $0.2-4$ & \multirow[b]{2}{*}{ Require standardization, unstable } & \multirow[b]{2}{*}{20} \\
\hline & $\begin{array}{l}\text { b) Chloramine-T- Xylene } \\
\text { cyanol FF }\end{array}$ & & 612 & $0.6-4$ & & \\
\hline 2 & Bromothymol blue & $\begin{array}{l}\text { Extractable ion-pair } \\
\text { complex measured }\end{array}$ & 412 & $10-50$ & $\begin{array}{l}\text { Require extraction, less sensitive, } \mathrm{pH} \\
\text { dependent }\end{array}$ & 21 \\
\hline 3 & Chromotrope 2R & $\begin{array}{l}\text { Methylene chloride } \\
\text { extractable ion-pair } \\
\text { complex measured }\end{array}$ & 512 & $30-120$ & $\begin{array}{l}\text { Less sensitive, required close } \mathrm{pH} \text { control } \\
\text { and involved extraction step }\end{array}$ & 22 \\
\hline \multirow{4}{*}{4} & a)bromothymol blue & & 409 & $0.5-9.0$ & \multirow{4}{*}{$\begin{array}{l}\text { Required close } \mathrm{pH} \text { control and involved } \\
\text { tedious time consuming extraction steps }\end{array}$} & \multirow{4}{*}{23} \\
\hline & b)bromophenol blue & Chloroform extractable & $4 I I$ & $1.0-6.0$ & & \\
\hline & c)bromocresol green & measured & 414 & $1.0-8.0$ & & \\
\hline & d)bromocresol purple & & $4 I I$ & $0.5-6.0$ & & \\
\hline \multirow[t]{4}{*}{6} & NBD-Cl & $\begin{array}{l}\text { Charge-transfer complex } \\
\text { measured }\end{array}$ & 946 & $10-50$ & $\begin{array}{l}\text { Requires heating, non-aqueous solvents and } \\
\text { less sensitive }\end{array}$ & 25 \\
\hline & $\begin{array}{l}\text { Bromate-bromide } \\
\text { mixture: }\end{array}$ & & & & & \\
\hline & a) lodide & $\begin{array}{l}\text { Yellow colored tri-iodate } \\
\text { ion measured }\end{array}$ & 360 & $\begin{array}{l}2.0-20.0(\varepsilon \\
=2.2 \times 104)\end{array}$ & \multirow{2}{*}{$\begin{array}{l}\text { Simple, sensitive and no heating step, no } \\
\text { standardization. No use of organic solvent. } \\
\text { Use of a green brominating reagent. }\end{array}$} & \multirow{2}{*}{ This Work } \\
\hline & b) Starch-iodide & $\begin{array}{l}\text { Blue colored starch-iodide } \\
\text { complex measure }\end{array}$ & 570 & $\begin{array}{l}0.6-6.0(\varepsilon \\
=5.3 \times 104)\end{array}$ & & \\
\hline
\end{tabular}

Table 2 Regression and analytical parameters

\begin{tabular}{lll}
\hline Parameter & Method A & Method B \\
\hline$I_{\text {max }}, \mathrm{nm}$ & 360 & 570 \\
Beer's law limits, $\mu \mathrm{g} \mathrm{ml^{-1 }}$ & $2-20.0$ & $0.6-6.0$ \\
Molar absorptivity $(\varepsilon) \mathrm{I} \mathrm{mol}^{-1} \mathrm{~cm}^{-1}$ & $2.2 \times 10^{4}$ & $5.3 \times 10^{4}$ \\
Sandell sensitivity,$\mu \mathrm{g} \mathrm{cm} \mathrm{cm}^{-2}$ & 0.0238 & $0.010 \mathrm{I}$ \\
Limit of detection (LOD), $\mu \mathrm{g} \mathrm{m}^{-1}$ & 0.2 & 0.08 \\
Limit of quantification (LOQ), $\mu \mathrm{g} \mathrm{ml}^{-1}$ & 0.6 & 0.25 \\
Regression equation, $\mathrm{Y}^{\mathrm{b}}$ & & 0.806 \\
Intercept, (a) & 0.9301 & \\
Slope, (b) & & -0.1057 \\
Correlation coefficient $(\mathrm{r})$ & -0.0436 & $-0.995 \mathrm{I}$ \\
Standard deviation of intercept $\left(\mathrm{S}_{\mathrm{a}}\right)$ & -0.9973 & 0.0896 \\
Standard deviation of slope $\left(\mathrm{S}_{\mathrm{b}}\right)$ & $0.006 \mathrm{I}$ & 0.0265
\end{tabular}

*Limit of determination as the weight in $\mu \mathrm{g}$ per $\mathrm{ml}$ of solution, which corresponds to an absorbance of $\mathrm{A}=0.00 \mathrm{I}$ measured in a cuvette of cross-sectional area $\mathrm{Icm}^{2}$ and $\mathrm{I}=\mathrm{Icm}$. **, where $\mathrm{Y}$ is the absorbance, $\mathrm{a}$ is the intercept, $\mathrm{b}$ is the slope and $\mathrm{X}$ is the concentration in $\mu \mathrm{g} \mathrm{ml}^{-1}$.

Table 3 Intra-day and inter-day precision and accuracy evaluation. Mean value of five determinations; b. Relative standard deviation (\%); c. Relative error (\%)

\begin{tabular}{|c|c|c|c|c|c|c|c|}
\hline \multirow{2}{*}{ Method } & \multirow{2}{*}{ FFH* Taken $\mathrm{mg} / \mu \mathrm{g} \mathrm{ml}^{-1}$} & \multicolumn{3}{|c|}{ Intra-Day $(n=5)$} & \multicolumn{3}{|c|}{ Inter-Day $(\mathrm{n}=5)$} \\
\hline & & FFH found ${ }^{a}$ & $\% \mathbf{R S D}^{\mathrm{b}}$ & $\% \mathbf{R E}^{\mathbf{c}}$ & FFH found ${ }^{a}$ & $\% \mathbf{R S D}^{\mathbf{b}}$ & $\%$ RE $^{c}$ \\
\hline \multirow{3}{*}{ A (Titrimetry) } & 9 & 8.89 & 1.77 & 1.21 & 8.82 & 1.96 & 2.62 \\
\hline & 18 & 17.66 & 1.06 & 1.79 & 17.56 & $\mathrm{I} .84$ & 2.41 \\
\hline & 27 & 26.36 & 1.58 & 2.34 & 26.29 & 2.28 & 2.64 \\
\hline \multirow{3}{*}{ B (Spectrophotometry) } & 8 & 8.05 & 1.56 & 0.73 & 8.06 & $\mathrm{I} .47$ & 0.75 \\
\hline & 12 & 12.07 & 1.15 & 0.63 & 12.14 & 2.16 & 1.16 \\
\hline & 16 & 15.78 & 1.08 & 1.34 & 15.7 & 2.27 & 1.89 \\
\hline \multirow{3}{*}{ C (Spectrophotometry) } & 2.4 & 2.44 & 1.29 & 1.85 & 2.47 & 1.85 & 2.89 \\
\hline & 3.6 & 3.68 & 1.14 & 2.33 & 3.7 & 1.81 & 2.71 \\
\hline & 4.8 & 4.84 & 0.68 & 1.91 & 4.86 & 2.38 & 1.28 \\
\hline
\end{tabular}

Citation: Raghu MS, Shantharam CS, Yogesh KK.Application of bromate-bromide mixture as a green brominating agent for the determination of fexofenadine hydrochloride in pharmaceutical dosage form. J Anal Pharm Res. 2018;7(I): I I-I2. DOI: I0.15406/japlr.2018.07.00 I93 
Method ruggedness was demonstrated by having the analysis done by four analysts, and also by a single analyst performing the analysis on four different burettes/cuvettes in the same laboratory. Intermediate precision values (RSD, \%) in both instances were in the range $0.64-2.94 \%$ indicating acceptable ruggedness. These results are presented in Table 4.

Selectivity: The placebo blank and synthetic mixture when subjected to analysis by the proposed methods did not reveal interference by the placebo components. The analysis of the synthetic mixture yielded percentage recovery values of FFH obtained from this study were in the range from 97.63 to 102.47 . This unequivocally demonstrated the non-interference of the inactive ingredients in the assay of FFH. Further, the slopes of the calibration plots prepared from the synthetic mixture solutions were about the same as those prepared from pure drug solutions.

Application: The proposed methods were applied to the quantification of FFH in commercial tablets. The results presented in Table 5 showed that the methods are successful to the determination of FFH in pharmaceutical formulations without any detectable interference from Table 4 Method robustness and ruggedness study (\%, RSD). ${ }^{*} m$ in titrimetry the excipients present in the tablets. The reference method describes the measurement of ethanolic solution of FFH at $220 \mathrm{~nm} .{ }^{19}$ When the results were statistically compared with those of the reference method by applying the Student's t-test for accuracy and F-test for precision, the calculated Student's t- value and F-value at 95\% confidence level did not exceed the tabulated values of 2.78 and 6.39 , respectively. Hence, no significant difference exists between the proposed methods and the reference method with respect to accuracy and precision.

Recovery study: To assess the accuracy of the methods, recovery experiments were performed by applying the standard-addition technique. To a fixed and known amount of FFH in tablet powder (pre-analyzed), pure FFH was added at three concentration levels (50, 100 and $150 \%$ of the level present in the tablet) and the total was measured by the proposed methods. The determination with each concentration was repeated three times. In all the cases, the recovery percentage values ranged between 97.65 and 102.4 with relative standard deviation in the range $1.02-2.08 \%$. The results of this study presented in Table 6 indicated that the various excipients present in the formulations did not interfere in the assay.

\begin{tabular}{|c|c|c|c|c|c|}
\hline \multirow[b]{2}{*}{ Method } & \multirow{2}{*}{$\begin{array}{l}\text { Nominal Amount } \\
\text { concentration } \mathrm{mg} / \mathrm{\mu g} \mathrm{ml-I*}\end{array}$} & \multicolumn{2}{|l|}{ Robustness (\%RSD) } & \multicolumn{2}{|l|}{ Ruggedness (\%,RSD) } \\
\hline & & $*$ Reaction times ${ }^{a}(n=3)$ & Volume of acidb & Different analysts $(n=4)$ & $\begin{array}{l}\text { Different Burettes/ } \\
\text { Cuvettes }^{c}(n=3)\end{array}$ \\
\hline & 9 & 2.64 & 1.28 & 0.64 & 1.72 \\
\hline \multirow[t]{3}{*}{ A } & 18 & 1.76 & 1.39 & 1.12 & 2.54 \\
\hline & 27 & 2.14 & 2.37 & 0.72 & 2.37 \\
\hline & 8 & 2.25 & 2.31 & 1.76 & 2.86 \\
\hline \multirow[t]{3}{*}{ B } & 12 & 2.44 & 1.84 & 2.12 & 2.14 \\
\hline & 16 & 2.58 & 2.13 & 1.42 & 2.52 \\
\hline & 2.4 & 1.85 & 2.05 & 1.17 & 2.76 \\
\hline \multirow[t]{2}{*}{ C } & 3.6 & 2.16 & 1.42 & 1.28 & 2.94 \\
\hline & 4.8 & 2.08 & 2.37 & 1.46 & 2.82 \\
\hline
\end{tabular}

aThe reaction time was 8,10 and $12 \mathrm{~min}$ all the three methods,

bVolume of $2 \mathrm{M} \mathrm{HCl}$ was 4,5 and $6 \mathrm{~mL}$ in method $\mathrm{A}$, and 0.8 . 1.0 and $1.2 \mathrm{~mL}$ in method $B$ and method $C$,

'Burettes in titimetry, cuvettes in spectrophotometry.

Table 5 Results of assay of tablets by the proposed methods and statistical evaluation.

\begin{tabular}{|c|c|c|c|c|c|}
\hline \multirow{3}{*}{$\begin{array}{l}\text { Tablet Brand } \\
\text { Name }^{\text {b }}\end{array}$} & \multirow{3}{*}{$\begin{array}{l}\text { Label } \\
\text { Claim* }\end{array}$} & \multicolumn{4}{|c|}{ Found $^{\text {a }}$ (Percent of Label Claim \pm SD) } \\
\hline & & \multirow{2}{*}{ Reference method } & \multicolumn{3}{|c|}{ Proposed methods } \\
\hline & & & Method A & Method B & Method C \\
\hline & & & $97.98 \pm 0.86$ & $98.78 \pm 1.42$ & $98.62 \pm 1.38$ \\
\hline \multirow[t]{3}{*}{ Allegra } & 180 & $99.36 \pm 1.65$ & $t=2.61$ & $\mathbf{t}=2.80$ & $\mathbf{t}=2.90$ \\
\hline & & & $F=3.68$ & $\mathbf{F}=1.35$ & $\mathbf{F}=1.42$ \\
\hline & & & $100.8 \pm 1.27$ & $100.65 \pm 1.58$ & $99.16 \pm 1.22$ \\
\hline \multirow[t]{2}{*}{ Allegra } & 120 & $100.4 \pm 1.86$ & $\mathbf{t}=2.09$ & $\mathrm{t}=2.79$ & $\mathbf{t}=2.94$ \\
\hline & & & $F=2.14$ & $\mathbf{F}=1.38$ & $F=2.32$ \\
\hline
\end{tabular}

*mg/tablet in tablets.

aMean value of five determinations,

${ }^{b}$ Aventis Pharma Ltd., India.

The value of $t$ and $F$ (tabulated) at $95 \%$ confidence level and for four degrees of freedom are 2.77 and 6.39, respectively.

Table 6 Recovery study via standard addition method

\begin{tabular}{|c|c|c|c|c|c|}
\hline Method & Tablet Studied & FFH in Tablet $\mu \mathrm{g} \mathrm{ml}^{-1}$ & Pure FFH Added $\mu \mathrm{g} \mathrm{ml}^{-1}$ & Total Found $\mu \mathrm{g} \mathrm{ml}^{-1}$ & Pure FFH* Percent \pm SD \\
\hline & & 8.82 & 4.5 & 13.08 & $98.24 \pm 1.98$ \\
\hline \multirow[t]{3}{*}{ A Titrimetry, } & Allegra-180 & 8.82 & 9 & 17.6 & $98.78 \pm 1.25$ \\
\hline & & 8.82 & 13.5 & 21.79 & $97.65 \pm 2.08$ \\
\hline & & 5.92 & 3 & 8.86 & $98.12 \pm 1.16$ \\
\hline B Spectrophotometry & Allegra-180 & 5.92 & 6 & 11.87 & $99.26 \pm 1.86$ \\
\hline & & 5.92 & 9 & 1.27 & $101.1 \pm 1.27$ \\
\hline
\end{tabular}


Table Continued...

\begin{tabular}{|c|c|c|c|c|c|}
\hline Method & Tablet Studied & FFH in Tablet $\mu \mathrm{g} \mathrm{ml}^{-1}$ & Pure FFH Added $\mu \mathrm{g} \mathrm{ml}^{-1}$ & Total Found $\mu \mathrm{g} \mathrm{ml}^{-1}$ & Pure FFH* Percent \pm SD \\
\hline & & 1.78 & 0.9 & 2.66 & $98.8 I \pm I .76$ \\
\hline C Spectrophotometry & Allegra-180 & 1.78 & 1.8 & 7.96 & $102.4 \pm 1.02$ \\
\hline & & 1.78 & 2.7 & 4.52 & $101.7 \pm 1.03$ \\
\hline
\end{tabular}

*Mean value of three determinations.

\section{Conclusion}

The present paper describes one titrimetric and two spectrophotometric methods for the determination of Fexofenadine hydrochloride in bulk drug and in its tablets and validated as per the current ICH guidelines. The methods use bromate-bromide mixture as a green brominating reagent instead of hazardous liquid bromine. The assay results demonstrated that it is possible to use bromate-bromide mixture as an environmental friendly reagent and potassium iodide and starch as auxillary reagents for the indirect titrimetric and spectrophotometric determination of FFH in authentic samples. The titrimetric method which incidentally the first ever proposed for $\mathrm{FFH}$, is much simpler method and it is applicable over a semi micro range $(4.5-30 \mathrm{mg} F F H)$, yet provides very accurate and precise results. Unlike most of the existing spectrophotometric methods, the proposed spectrophotometric procedures are sensitive, simple, use eco-friendly chemicals, free from organic solvents and unwelcome steps such as heating or extraction and also from critical $\mathrm{pH}$ conditions. The spectrophotometric method $\mathrm{C}$ is more sensitive than the spectrophotometric method B as can be seen from the molar absorptivity values of both methods. The proposed methods rely on the inexpensive techniques and have the advantages of simplicity, cost-effectiveness and easily accessible technique in under-developed and developing countries. These advantages coupled with good accuracy and precision make the proposed methods highly suitable for routine use in laboratories as a part of industrial quality control.

\section{Acknowledgments}

None.

\section{Conflicts of interest}

The author declares no conflicts of interest.

\section{References}

1. Merck. The Merck Index, an Encyclopedia of Chemicals, Drugs, and Biologicals. Merck \& CO., INC., Whitehouse Station, New Jersey, USA. 2001

2. Dollery C. Therapeutic drugs. 2nd edn, Churchill Livingstone, UK, 1999. pp. A151-A154.

3. The United States Pharmacopoeia. XXIV Revision, The National Formulary XIX Rockville, USP Convention, USA. 2000

4. Breier AR, Paim CS, Steppe M, et al. Development and validation of dissolution tests for fexofenadine hydrochloride capsules and coated tablets. J Pharm Pharmaceut Sci. 2005;8(2):289-298.

5. Maher HM, Sultan MA, Olah IV. Development of validated stabilityindicating chromatographic method for the determination of fexofenadine hydrochloride and its related impurities in pharmaceutical tablets. Chem Cent J. 2011;3:5:76

6. Radhakrishna T, Om Reddy G. Simultaneous determination of fexofenadine and its related compounds by HPLC. J Pharm Biomed Anal. 2002;29(4):681-690.

7. Zafar F, Shoaib MH, Yousuf RI. Development of Rp-HPLC method for fexofenadine determination in tablet formulations and development of dissolution method. Pak J Pharmacol. 2001;28:43-49.
8. Vaghela B Rao SS, Reddy AM, Venkatesh P, et al. Identification and characterization of an oxidative degradation product of fexofenadine, development and validation of a stability-indicating RP-UPLC method for the estimation of process related impurities and degradation products of fexofenadine in pharmaceutical formulations. Sci pharmaceut. 2012;80(2):295-309.

9. Karakuş S, Küçükgüzel I, Küçükgüzel SG. Development and validation of a rapid RP-HPLC method for the determination of cetirizine or fexofenadine with pseudoephedrine in binary pharmaceutical dosage forms. J Pharm Biomed Anal. 2008;46(2):295-302.

10. Sharaf El- Din MK, Ibrahim F, Eid MI, et al. Validated stability indicating liquid chromatographic method for the determination of fexofenadine hydrochloride in presence of its degradation products. Application to tablets and content uniformity testing. J Pharmacy Research. 2011;4(7):2377-2380.

11. Oliveira DC, Weigch A, Rolim CM. Simple and reliable HPLC analysis of fexofenadine hydrochloride in tablets and its application to dissolution studies. Pharmazie. 2007;62(2):96-100.

12. Cui L, Qian L, Hong-wei S, Lun Y, et al. Determination of fexofenadine hydrochloride and its related substances by HPLC. Chinese Journal of New Drugs. 2007.

13. Arayne MS, Sultana N, Shehnaz H, et al. RP-HPLC method for the quantitative determination of fexofenadine hydrochloride in coated tablets and human serum. Med Chem Res. 2011;20(1):55-61.

14. Zeid Abdullah Alothman, Nausheen Bukharia, Sajjad Haider, et al. Spectrofluorimetric determination of fexofenadine hydrochloride in pharmaceutical preparation using silver nanoparticles. Arabian Journal of Chemistry. 2010;3(4):251-255.

15. Peter Mikuš, Iva Valášková, Emil Havránek. Determination of fexofenadine in tablets by capillary electrophoresis in free solution and in solution with cyclodextrins as Analyte Carriers. Drug Dev Ind Pharm. 2005;31(8):795-801.

16. Golcu A, Dogan B, Ozkan SA. Anodic voltammetric behavior and determination of antihistaminic agent:fexofenadine $\mathrm{HCl}$. Anal Lett. 2005;38:1913-1931.

17. Kozan İ, Palabiyik LM, Karacan E, et al. Spectrophotometric and high performance liquid chromatographic determination of fexofenadine hydrochloride in pharmaceutical formulations. Turk J Pharm Sci. 2008;5:175-189.

18. Vekaria HJ, Muralikrishna KS, Patel GF. Development and validation of spectrophotometric method for estimation of fexofenadine hydrochloride and montelukast sodium in combined dosage form. Inventi Impact:Pharm Ana \& Qual Assur. 2011.

19. Breier AR, Steppe M, Schapoval EES. Validation of UVSpectrophotometric method for fexofenadine hydrochloride in pharmaceutical formulations and comparison with HPLC. Analytical Letters. 2007;40(12):2329-2337.

20. Abbas MN, Abdel Fattah AA, Zahran E. A novel membrane sensor for histamine H1-receptor antagonist fexofenadine. Anal Sci. 2004;20(8):1137-1142.

21. Narayana B, Veena K. A new method for the spectrophotometric determination of fexofenadine hydrochloride. Indian Journal of Chemical Technology. 2010;17:386-390.

22. Suresh Kumar K, Ravichandran V, Mohan Maruga Raja MK, et al. Spectrophotometric determination of Fexofenadine hydrochloride. Ind J Pharm Sci. 2006;73(3):300-302. 
23. Soad S Abd El-Hay, Magda Y El-Mammli, Abdalla AS Spectrophotometric determination of clemastine hydrogen fumarate, fexofenadine $\mathrm{HCl}$ and moxepril $\mathrm{HCl}$ through ion-pair formation with Chromatrope 2R. Research Journal of Pharmaceutical Biological and Chemical Sciences. 2011;2:497-509.

24. Alaa SA, Ibrahim SA, Hassan AM. Utility of extracted colored ion - associate complexes formation reaction for the determination of fexofenadine hydrochloride in pure forms and in dosage forms. $J$ Chem Eng Process Technol. 2010;1:101.

25. Srinivas LD, Ravi kumar P, Sastry BS. Ion association methods for the determination of fexofenadine in pharmaceutical preparations. $E$ Journal of Chemistry. 2005;2(3):199-202.

26. Saleh HM, Henawee MM, Ragab GH, et al. Utility of NBD-Cl for the spectrophotometric determination of some skeletal muscle relaxant and antihistaminic drugs, Spectrochim. Spectrochimica Acta Part A:Molecular and Biomolecular Spectroscopy. 2007;67(5):1284-1289.

27. Abdel H, Soad S, El-Mammli MY, et al. Spectrophotometric determination of desloratadine, fexofenadine HCL, etodolac, moexipril HCL and thiocolchicoside in pure and pharmaceutical formulations. Biosciences, Biotechnology Research Asia. 2011;8(1):49-58.

28. Saleh HM, El-Henawee MM, Ragab GH, et al. Effective spectrophotometric determination of some antihistaminic and skeletal muscle relaxant drugs through ion-pair formation with xylene cyanol and orange G. Bulletin of the Faculty of Pharmacy (Cairo University). 2007;45:377-390.
29. Basavaiah K, Tharpa K, Hiriyanna SG, et al. Spectrophotometric determination of lisinopril in pharmaceuticals using ninhydrin-a modified approach. J Food Drug Anal. 2009;17:93-99.

30. Sameer AMA, Basavaiah K. Use of bromate-bromide mixture as a reagent for the determination of dothiepin hydrochloride in pharmaceuticals. Thai J Pharm Sci. 2011;35:147-158.

31. Prashanth KN, Basavaiah K. Sensitive spectrophotometric determination of atenolol in pharmaceutical formulations using bromate-bromide mixture as an eco-friendly brominating agent. J Anal Meth Chem. 2012.p. 12.

32. Zenita Devi O, Basavaiah K, Vinay KB. Utilization of bromination reaction for the spectrophotometric assay of domperidone in pharmaceuticals. Chemical Industry \& Chemical Engineering Quarterly. 2011;17(1):81-89

33. El-Didamony AM. A sensitive spectrophotometric method for the determination of propranolol $\mathrm{HCl}$ based on oxidation bromination reaction. Drug Test Anal. 2010;2:122-129.

34. ICH. Validation of analytical procedures: Test and methodology. International Conference on Harmonization, London, UK. 1996. 